\title{
أنماط تطوير المناهج الدراسية وتنفيذها في التربية الدينية الإسلامية في المدرسة المثتوسة المحمدية ديفوك يوكياكرتا
}

M. Sayyidul Abrori ${ }^{1}$, Moh. Solikul Hadi' ${ }^{2}$, Abdul Kahfi Amrulloh ${ }^{3}$

${ }^{1}$ UIN Sunan Kalijaga Yogyakarta, ${ }^{2}$ UIN Sunan Kalijaga Yogyakarta, ${ }^{3}$ IAIN Pekalongan

1,2 Jl. Laksda Adisucipto, Papringan, Caturtunggal, Kec. Depok, Kabupaten Sleman, Daerah Istimewa Yogyakarta

${ }^{3}$ Jl. Kusuma Bangsa No. 9, Panjang Baru, Pekalongan Utara, Kota Pekalongan arori400@gmail.com¹, mohsolikulhadi@gmail.com², amrullohsidul@gmail.com ${ }^{3}$

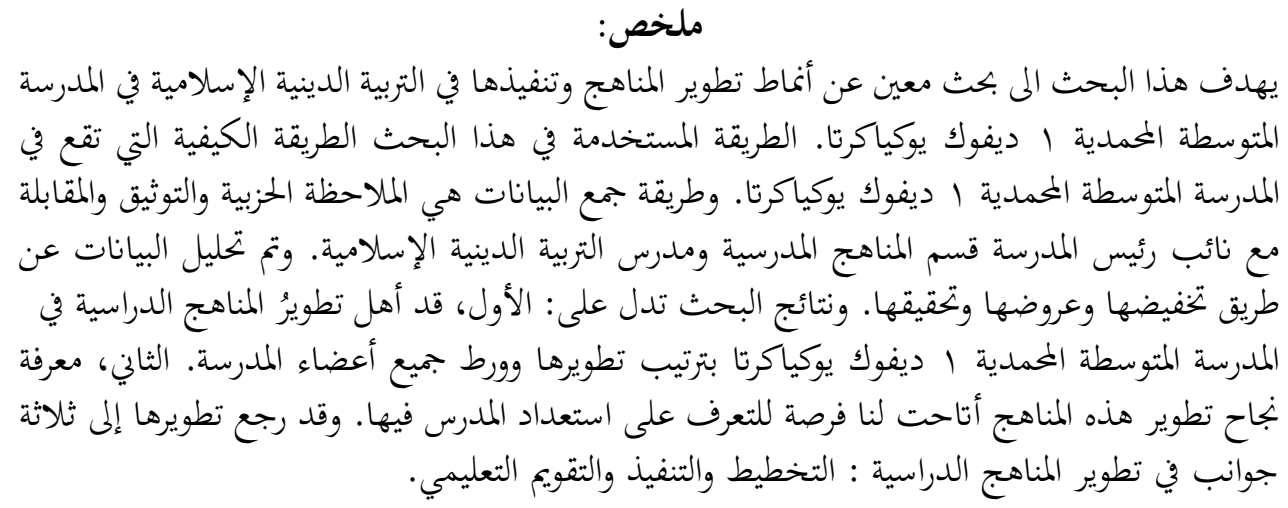

Abstrak:

Penelitian ini bertujuan untuk mengkaji tentang pengembangan kurikulum dan implementasinya dalam Pendidikan Agama Islam di Sekolah Menengah Pertama Muhammadiyah 1 Depok Yogyakarta. Metode yang digunakan dalam penelitian ini adalah kualitatif dan mengambil lokasi di Sekolah Menengah Pertama Muhammadiyah 1 Depok Yogyakarta. Metode pengumpulan data (yang digunakan) adalah observasi lapangan, dokumentasi, dan wawancara dengan Wakil Kepala Sekolah Bidang Kurikulum dan guru Pendidikan Agama Islam. Data dianalisis dengan cara mereduksi, menyajikan, dan memverifikasi/menyimpulkan. Hasil penelitian menunjukkan: Pertama, pengembangan kurikulum SMP Muhammadiyah 1 Depok Yogyakarta telah sesuai dengan langkah-langkah atau urutan dalam pembuatan kurikulum dan juga melibatkan semua stakeholder sekolah tersebut. Kedua, mengetahui keberhasilan pengembangan kurikulum tersebut memberi kesempatan bagi kita untuk belajar tentang kesiapan guru. Pengembangan kurikulum tersebut mencakup tiga aspek, yaitu: perencanaan, implementasi, dan evaluasi pendidikan.

$$
\begin{aligned}
& \text { كلمات مفتاحية: } \\
& \text { التطوير، التنفيذ، المناهج الدراسية }
\end{aligned}
$$

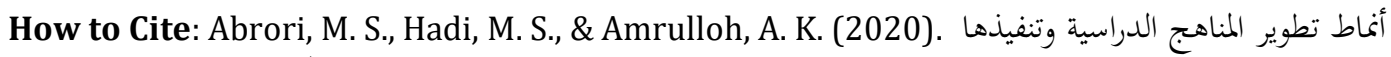
. . مي التربية الدينية الإسلامية قي المدرسة المتوسطة المحمدية ا ديفوك يوكياكرتا Tarbiyah dan Keguruan, 23(1), 183-193. https://doi.org/10.24252/lp.2020v23n1i15. 
يقول الله عز وجل في القرآن الكريم (البقرة : . ب) إن الإنسان هو خليفة الله في الأرض. المراد أن

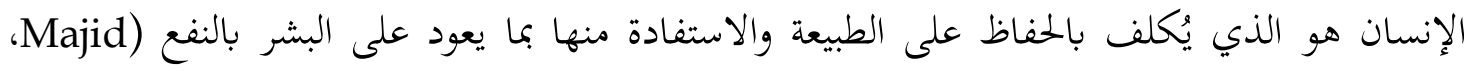

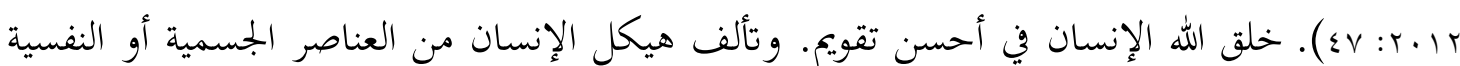

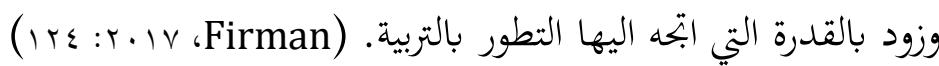
النجاح عند الشعب استهدف لتنظيم تربيته وتعليمه. التربية لما دور مهم في مساعدة فرد أو مجموعة التها في تطوير وجهة النظر عن الحياة والمهارات ومن ناحية التربية الإسلامية يجبون أن يناسبوا بالقرآن والسنة.

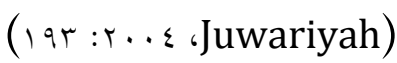
جرت التربية الإسلامية وتتطور مع تطور الإسلام والثقافة الاجتماعية في المجتمع. ارتفاع قيمة التربية

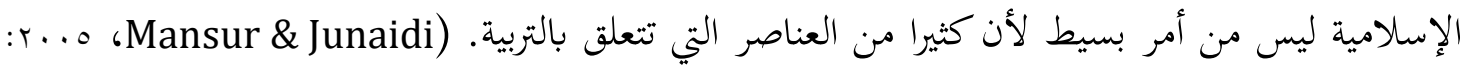
V) وجربت المدرسة بعض الكيفيات لارتفاع قيمة التربية الإسلامية، كتنظيم المناهج الدراسية. تتأثر جودة التعليم الديني الإسلامي إلى حد كبير بكيفية تطوير المؤسسة التعليمية في المناهج التي تتوافق مع متطلبات المجتمع، مما يجعل الطلاب أكثر تفوقا. المناهج الدراسية هي إحدى العناصر المهمة في التربية. ووضع المناهج في وسط التربية على تحقيق الغاية وهدف التربية المنشودة. و في البحث العلمي الذي كتبه Sri Wahyuni قالت فيه أن المناهج الدراسية احدى المجموعات الذي يتكون فيها من التخطيط، والتنفيذ والتقويم في العملية التربوية

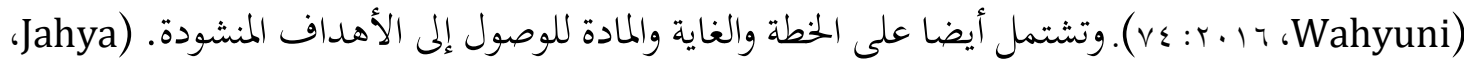
(乏: r... وتتغير أغراض المناهج الدراسية وفقا للتغير الاجتماعي الذي يرجع أسبابه إلى العوامل الداخلية أو

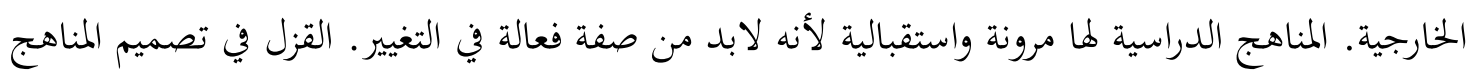
الدراسية تسبب قلة الردود في تغيير المجتمع وضعف نتائج التربية في تأهيل البيئة الدراسية (Bahri)، الا.ب ؟:

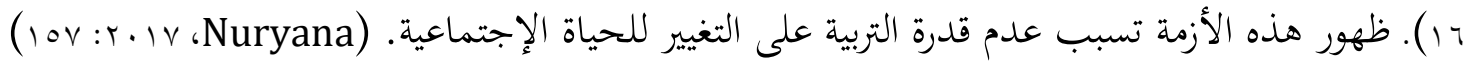

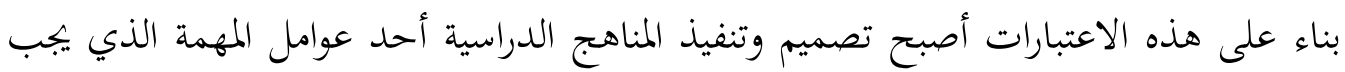
تطبيقه في التعليم. قال Handoko Ja'far أن تطوير او تغيير المناهج يأثر الى تحليلين وهما القبول والدفع. أصبحت المناهج والتربية راكدة اذ تفعهما تطوير او تغيير، وجعلهما أكثر تنوعا ونمودجيا إذ يقبلهما المناهج

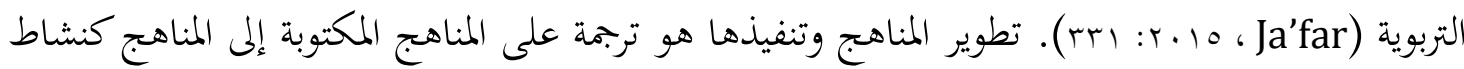
أو واقع. وكل هذه الأنشطة تعتمد الى ابتكار واجتهاد المدرس. المدرسة المتوسطة المحمدية ا ديفوك يوكياكرتا (Musade) إحدى المدارس التي تطور وتنفذ المناهج لتحصل على غرض المدرسة وهدفها. استعملت المدرسة (Musade) في سنة I 1 . المناهج الدراسية 
الإسلامية المحمدية واللغة العربية (ISMUBA) كالمناهج الدراسية للتربية الإسلامية بجانب المناهج الحكومية.

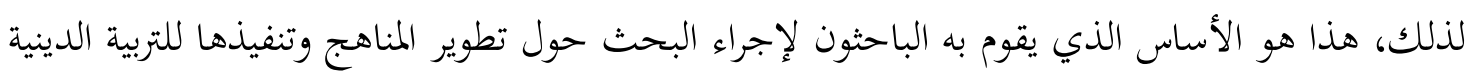
الإسلامية في المدرسة المتوسطة المحمدية الديفوك سليمان يوكياكرتا.

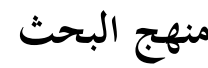

يستخدم الباحثون في إعداد بحثهم بمنهج البحث الكيفي. يقع هذا البحث في المدرسة المتوسطة

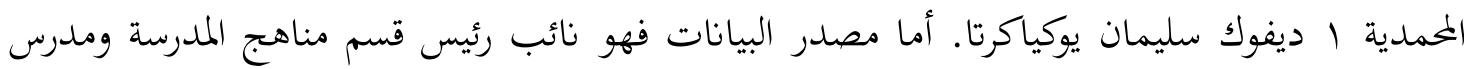

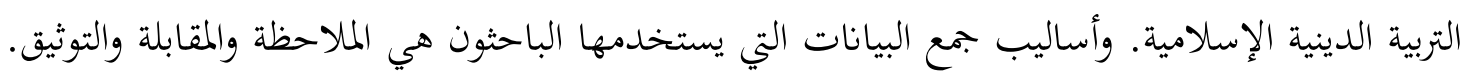
وتحليل البيانات بتخفيض وعروض وتحقيق البيانات.

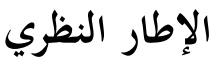

بداية تطوير المناهج الدراسية من المظاهر الإجتماعية و تغير جودة التربية. وصحة تطويرها تعطيى

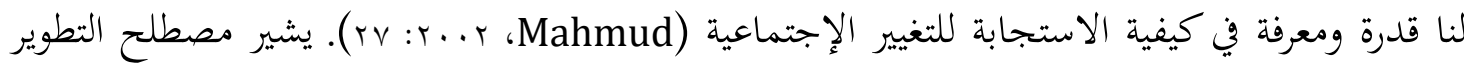

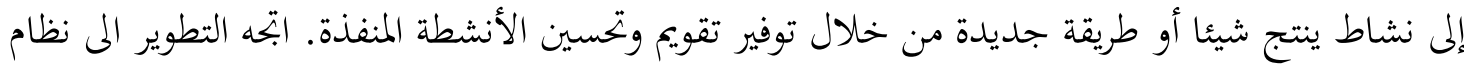

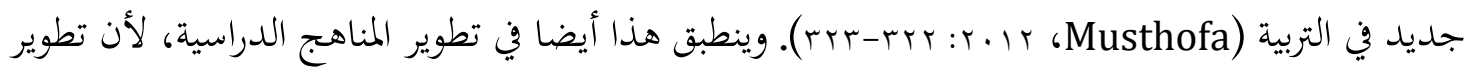

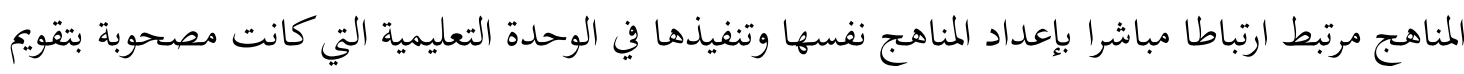

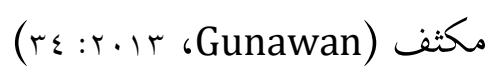

تطوير المناهج هو عملية تخطيط المناهج لإنتاج مناهج واسعة ومحددة. وهذه العملية العماتية تتصل باختيار

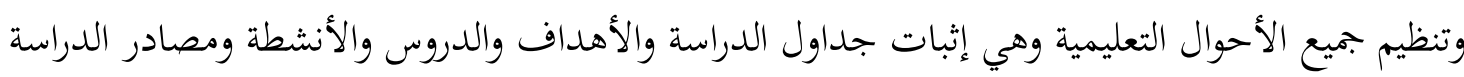

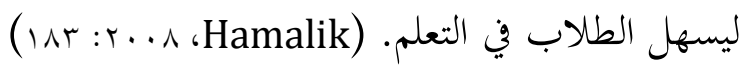

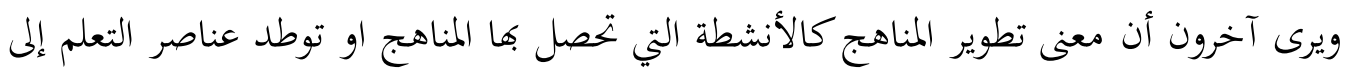

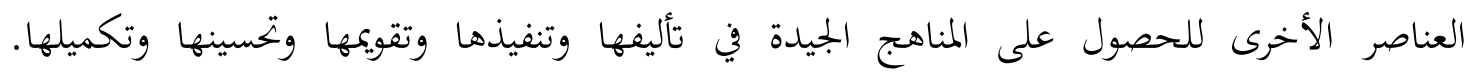
(1. : r...V،Muhaimin) يجوز للمؤسسة التعليمة تطوير المناهج الدراسية باستخدام مبادئ مختلفة من المؤسسة التعليمة

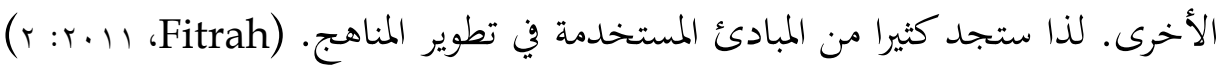

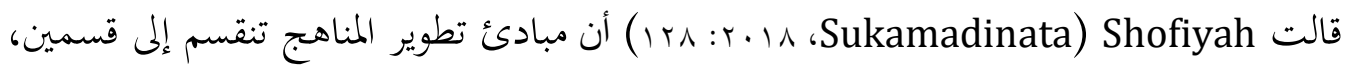

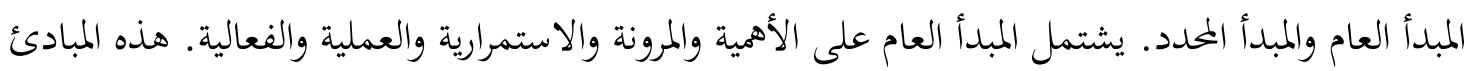

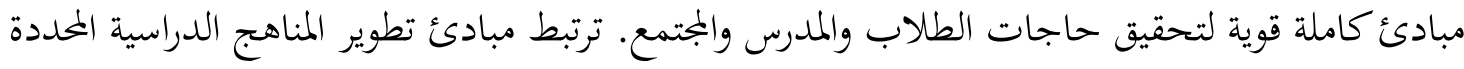

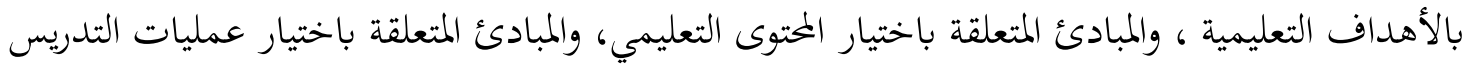

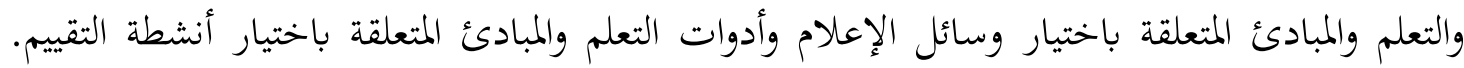


والتمسك بالمبدأ ستكون المهارات وموارد بشرية موثوقة ويستطيع ان يحقق أهداف التنمية الوطنية (^. : r. 10 ،Prihantoro)

خلال ذلك، التنفيذ موجه إلى التطبيق والاستعمال. التنفيذ هو عملية تنفيذ الأفكار أو المفاهيم

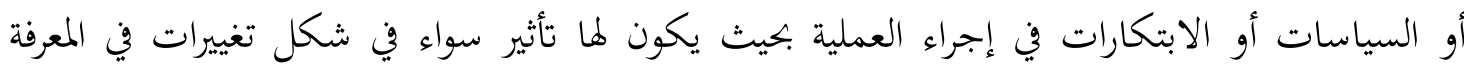

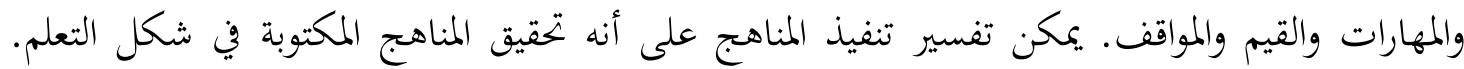
( $r$ II: r..r ، Kunandar)

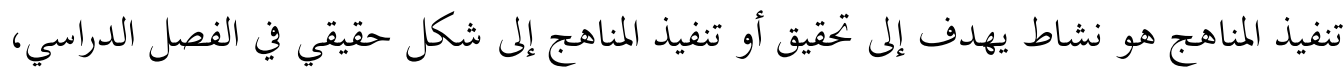

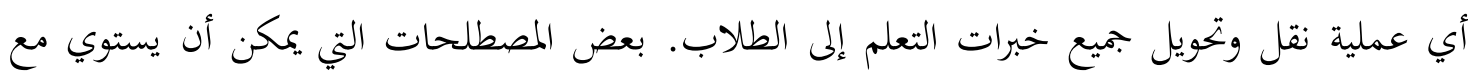
مصطلح تنفيذ المناهج هي التعلم.

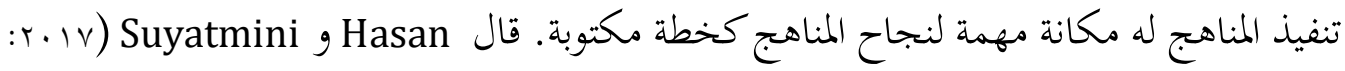

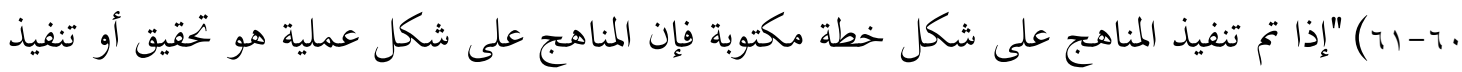

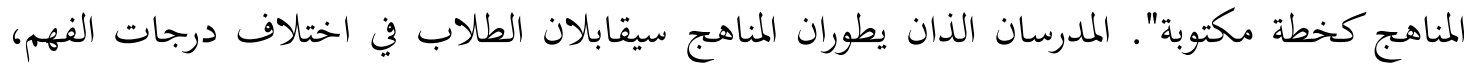

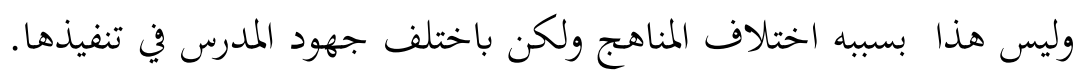

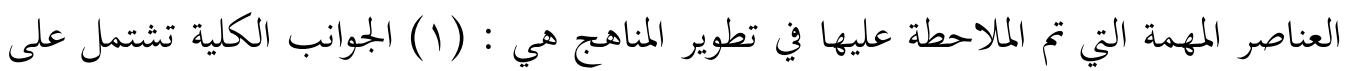

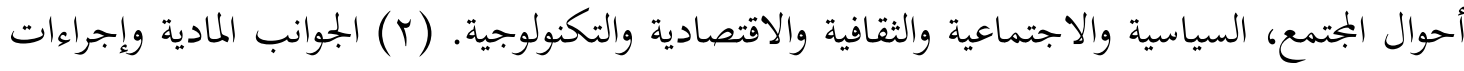

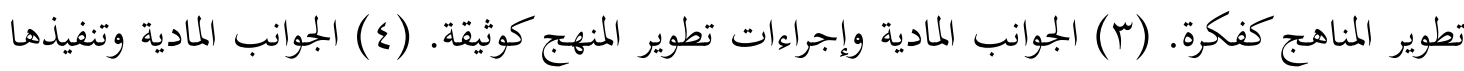

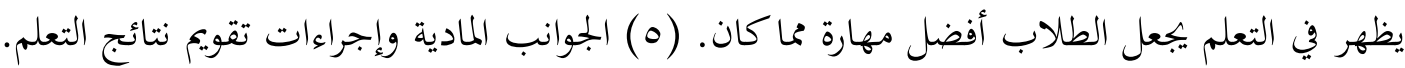

نتائج البحث ومناقشتها

مناهج التربية الدينية الإسلامية وتطويرها في الملدرسة المتوسطة المحمدية 1 ديفوك (Musade)

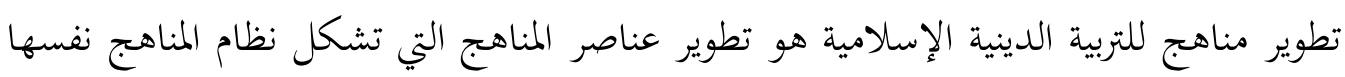

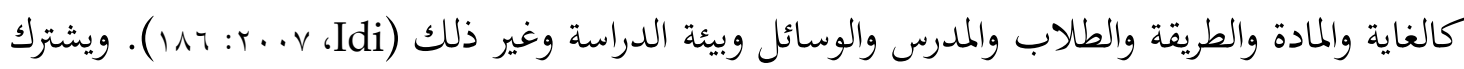

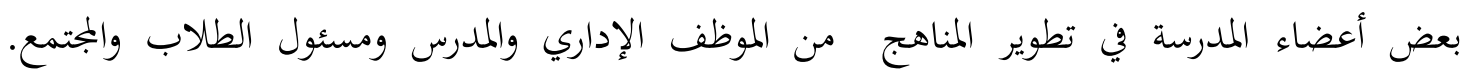
(100:r.1r، Sukmadinata) تستخدم المدرسة المناهج الدراسية أصدرها إدارة الشؤون التربوية بإندونيسيا و مجلس التربية الابتدائية

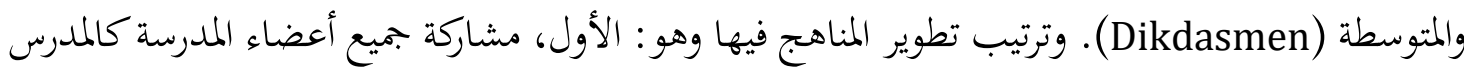

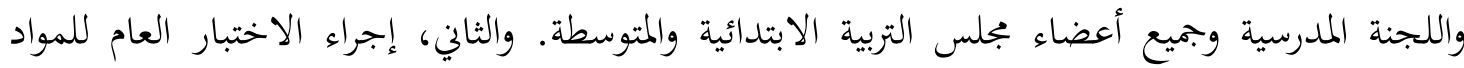

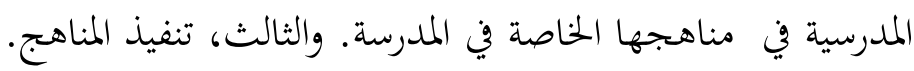


التحليل على نتائج المقابلة السابقة في المدرسة المتوسطة المحمدية ا ديفوك (Musade) يدل على المبلى

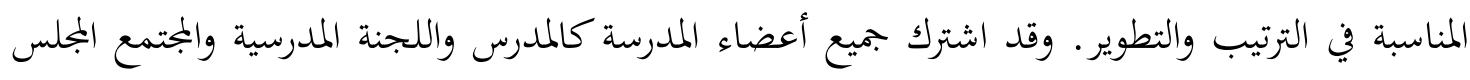
التربية الإبتدائية والمتوسطة.

سوف تتطور المناهج دائما، ومن غير المتمل أن تكون راكدة، لأن المجتمع كمجموعة من الناس

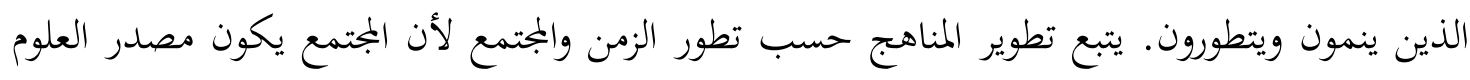
والتجارب ومنه سوف تحلله المدرسة للحصول على تلى المناهج الجديد الميدة.

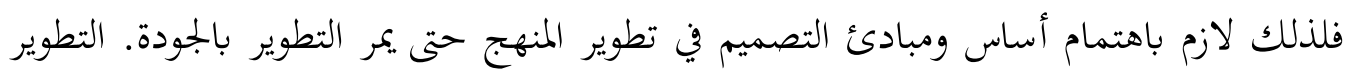

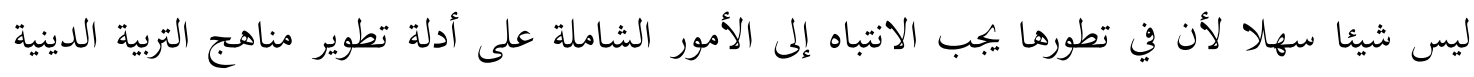

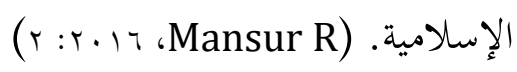

بناء على ذلك، فإن تطوير المناهج فيها قد قم من خلال تكامل المناهج الدراسية من ادارة الشؤون

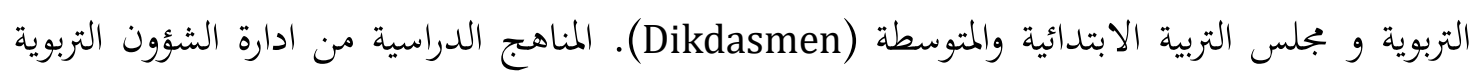

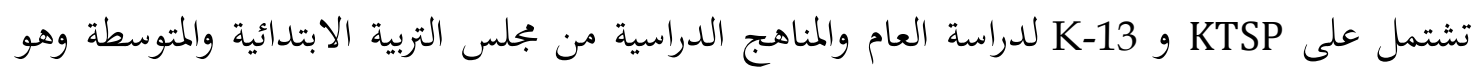

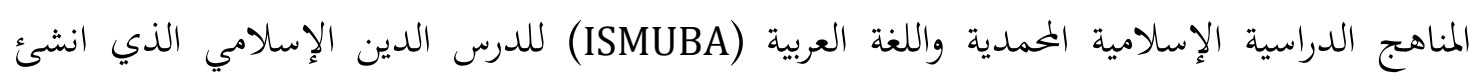

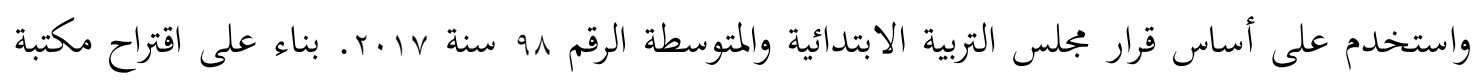

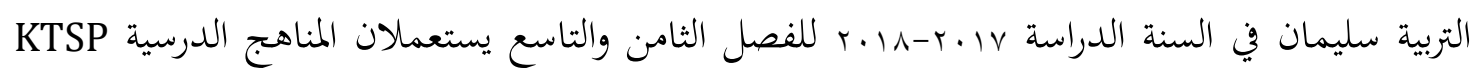

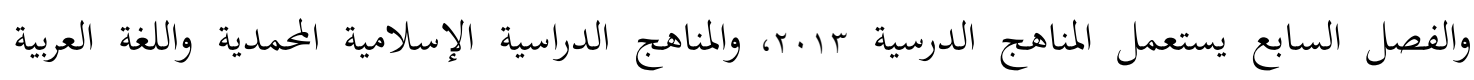
تستعمل في كل مرحلة. بناء على نتائج توثيق البحث، فإن هيكل فيكل المناهج الدراسية الإسلامية المحمدية واللغة العربية

ما يلي: (ISMUBA)

\begin{tabular}{|c|c|c|c|c|c|c|c|}
\hline \multicolumn{6}{|c|}{ الفصل والفصل الدراسي والوقت } & \multirow{3}{*}{ 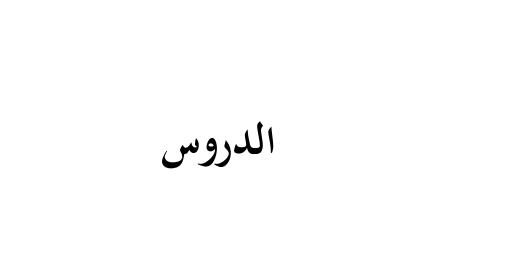 } & \multirow{3}{*}{ 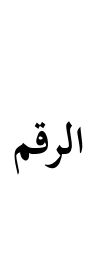 } \\
\hline \multicolumn{2}{|c|}{ IX } & \multicolumn{2}{|c|}{ VIII } & \multicolumn{2}{|c|}{ VII } & & \\
\hline 2 & 1 & 2 & 1 & 2 & 1 & & \\
\hline 3 & 3 & 3 & 3 & 3 & 3 & القرآن (التحسين التلاوة والتحفيظ) & 1 \\
\hline 2 & 2 & 2 & 2 & 2 & 2 & العقيدة والاخلاق & 2 \\
\hline 3 & 3 & 3 & 3 & 3 & 3 & تربية الفقه & 3 \\
\hline 1 & 1 & 1 & 1 & 1 & 1 & ت ت تربية التاريخ & 4 \\
\hline
\end{tabular}




\begin{tabular}{|c|c|c|c|c|c|c|c|}
\hline 1 & 1 & 1 & 1 & 1 & 1 & التربية المحمية & 5 \\
\hline 2 & 2 & 2 & 2 & 2 & 2 & اللغة العربية & 6 \\
\hline 12 & 12 & 12 & 12 & 12 & 12 & عدد & \\
\hline
\end{tabular}

المراد من الجمدول السابق أن هذه المدرسة قد تطور المناهج الدراسية التكاملية بين العلوم العامة والعلوم الدينية. والعوامل التي تطور في المناهج الدراسية الإسلامية المحمدية واللغة العربية (ISMUBA) هي هي

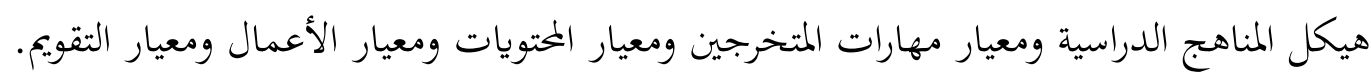
المناهج الدراسية الإسلامية المحمدية واللغة العربية (ISMUBA) هي مادة التربية الأصولية لنظام التربية المحمدية التي لما وظائف لتوجيه الطلاب حتى يكونوا طلابا مؤمنين ومتقين الله ومتخلقين بأخلاق كريمة وعاملين بأعمال إسلامية يوميا على أساس القرآن والسنة. وهذه المناهج يجب أن يدرسها طلاب المدرسة المحمدية. تتكون مواد هذه المناهج الدراسة على يلى

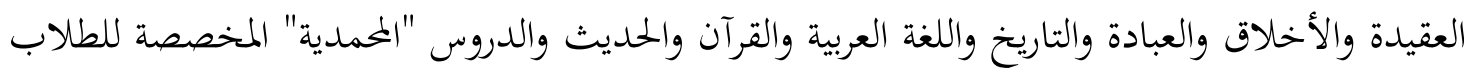

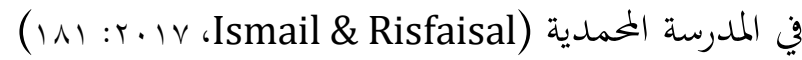

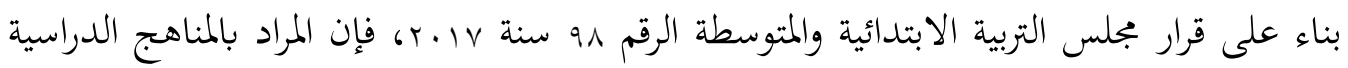
الإسلامية المحمدية واللغة العربية (ISMUBA) هي : بناء يشتمل على معيار مهارات المتخرجين على إجراء الأقل من كل مرحلة للدروس الإسلامية المحمدية

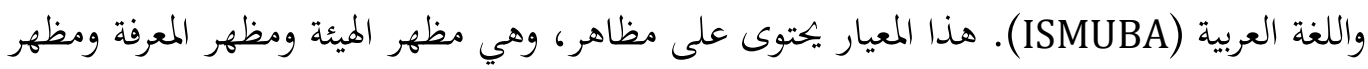

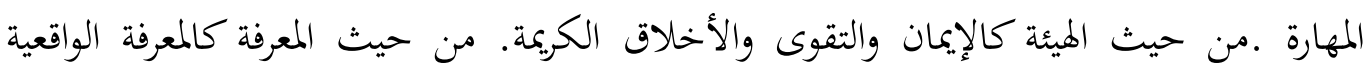
والمفاهيم والإجراءات وغير ذلك. ومظهر المهارة كالتفكير والابتكارية وكثيرة الانتاج والنقد

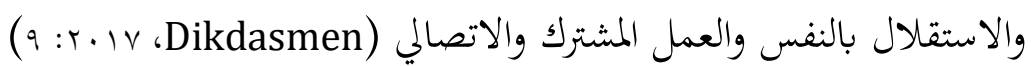
يشتمل معيار المحتويات على مجال المادة ومعيار ليبلغ مهارات المتخرجين في المرحلة التعليمية. يتكون معيار المحتويات إلى المهارات الأساسية (KI) والمهارات الأصولية (KD). Dikdasmen). $(11: r \cdot 1 \mathrm{~V}$ معيار العمل في هذه المدرسة يقام بتكامل وشاملة بين الدروس والأنشطة المدرسية. يشتمل معيار

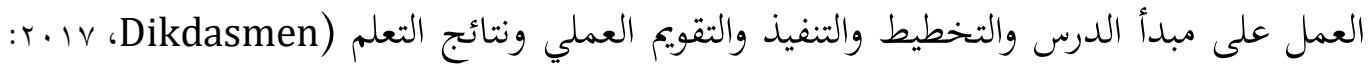
يشتمل معيار التقويم على مجال إرشاد التقويم الذي يحتوى على مبدأ تقويم ISMUBA، وتقويم لمدرس ISMUBA ومعيار الهيئة والمعرفة والمهارة ومعالجة نتائج التقويم واستخدام متابعة نتائج التقويم،

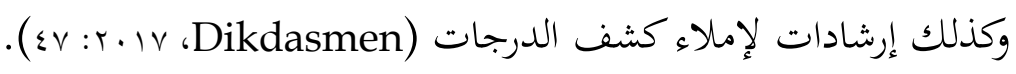


العوامل التي تؤثر نجاح التربية تنقسم إلى قسمين : العوامل المساعدة والعوامل العائقة. بناء على العلى

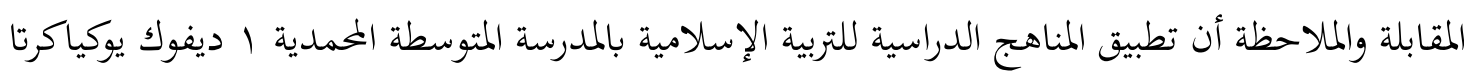

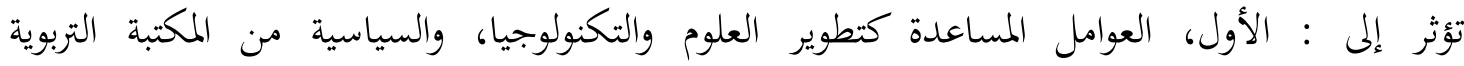

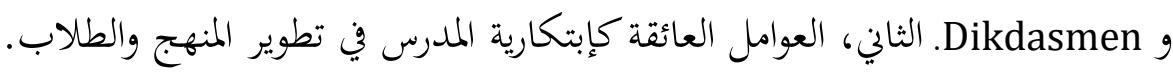

مناهج التربية الدينية الإسلامية وتنغيذها في الملدوسة المتوسطة المحمدية إنيفوك (Musade)

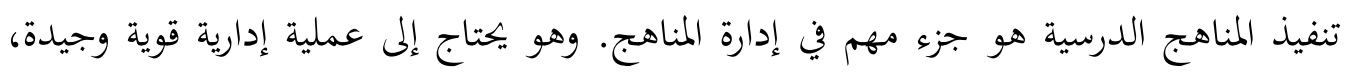

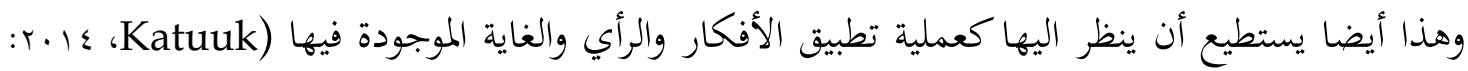

قد استعد مدرس التربية الدينية الإسلامية استعدادا كبيرا في تنفيذ المناهج. نرى حقيقة هذه العبارة

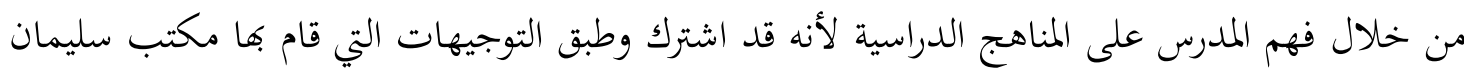

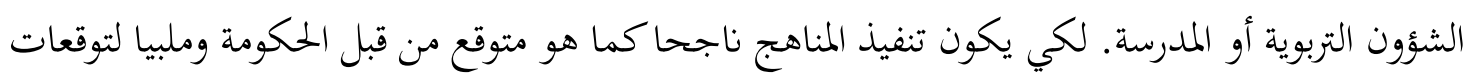

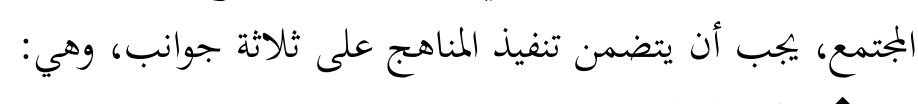
التخطيط

قبل بداية الدرس، استعد مدرس التربية الدينية الإسلامية بإنشاء تجهيزات الدرس كالمقرر الدراسي

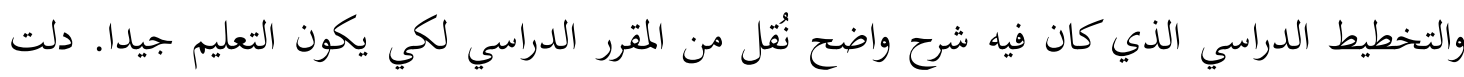

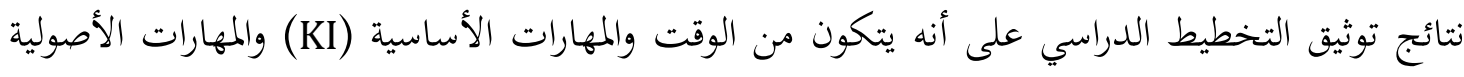

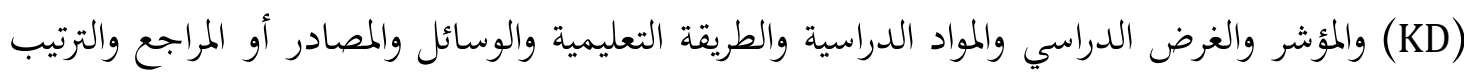
التعليمي والتقويم.

التحليل على التوثيق السابق يدل على أن المدرس استعد بالدرس استعداد جيدا فلذلك تنفيذ

المناهج من ناحية تخطيطها جيدا.

التنفيذ تاحية

تم تنفيذ المناهج الدراسية في التربية الدينية الإسلامية لتحقيق الغرض أو الهدف من التربية القومية

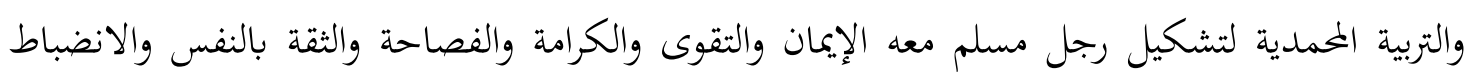

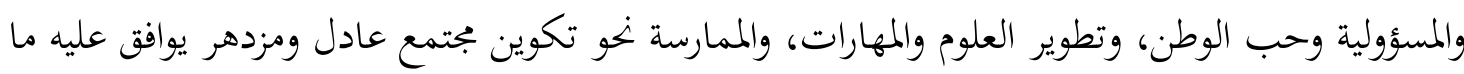
أراده الله تعالى وإنتاج موارد بشرية موثقة.

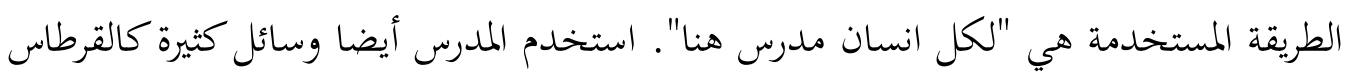

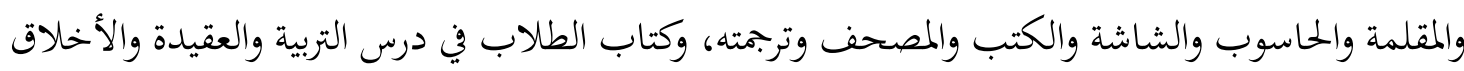

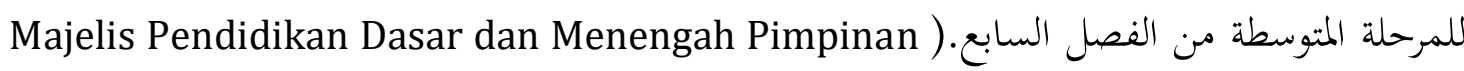


Pusat Muhammadiyah dan Yunahar Ilyas (LPPI UMY). بناء على نتائج التوثيق السابق فإن المدرس يستخدم الطريقة والوسائل المتنوعة ليجعل التعليم يجري جريا فعالا. - الا.

ومن خلال ذلك، تنفيذ المناهج الدراسية يؤكد على وقاية التربية الشخصية. ووجد تنفيذها في

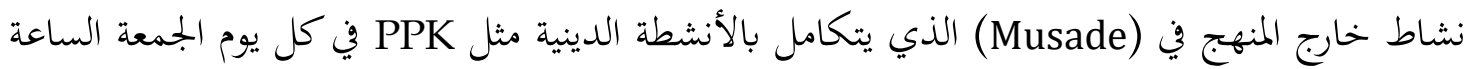

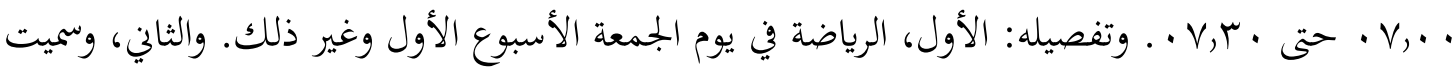

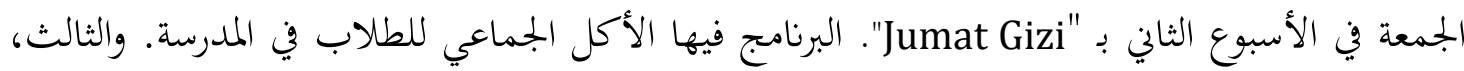
سميت الجمعة في الأسبوع الثالث بـ "Jumat kerja bakti" وكل أعضاء المدرسة ينظفون البيئة المدرسية.

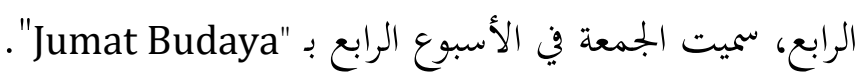
التقويم

بناء على نتائج المقابلة التي تم إجراؤها يظهر أن تقويم عملية التعلم (Musade) يتم وفقا لصيغة

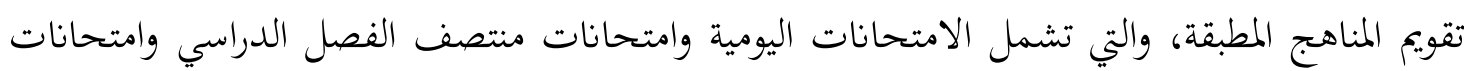

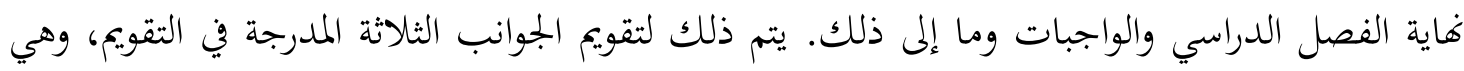

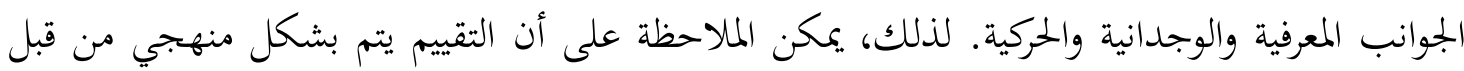

المعلم ووحدة التعليم، أي بجلس Dikdasmen.

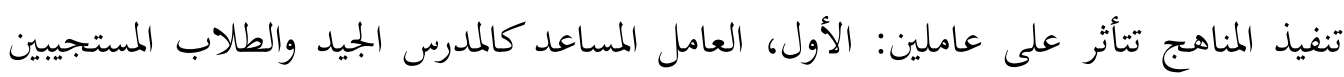

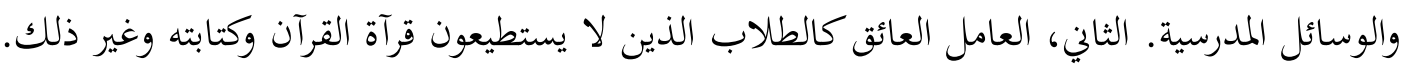
تقويم التعلم ونتائجه يقاس من خلال تحقيق الكفائة. التخطيط الكفائي والمهارات عند المناهي الماته :

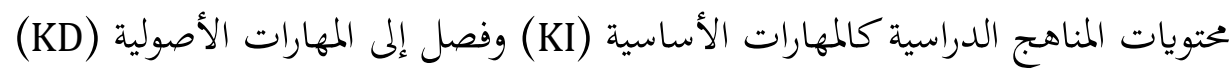

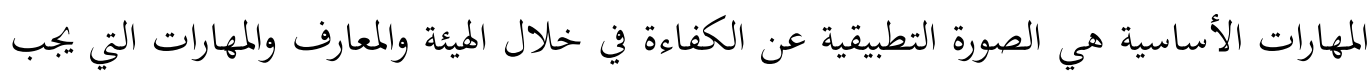

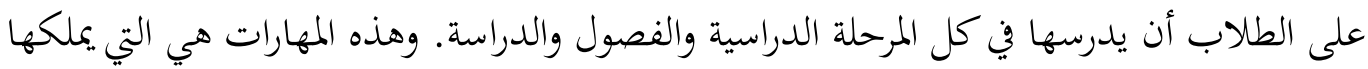

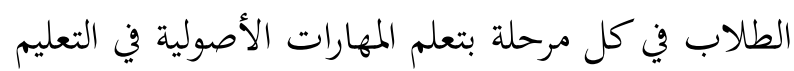

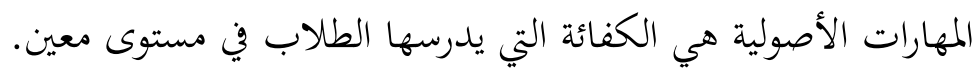

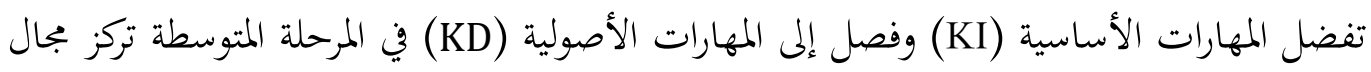

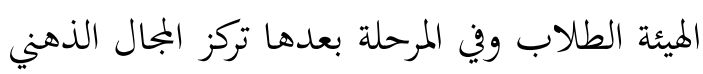

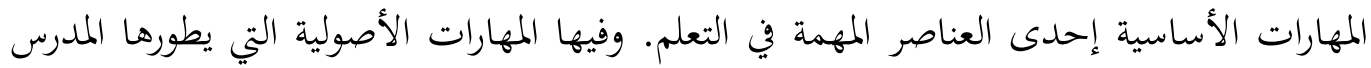
ليبلغ الكفائة في تلك المرحلة. تستند المهارات الأصولية التي تم تطويرها على مبدأ التراكم والتأكيد بين الدروس والمرحلة التعليمية. 
يتطور المقرر الدراسي كتخطيط التعلم في وموضع واحد (SD/MI) أو لكل فصل و درس • (SMP/MTs, SMA/MA, SMK/MAK)

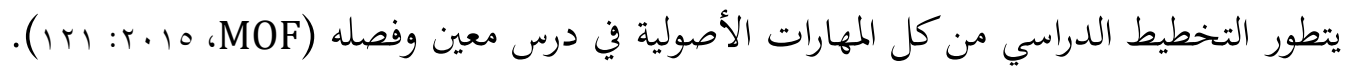

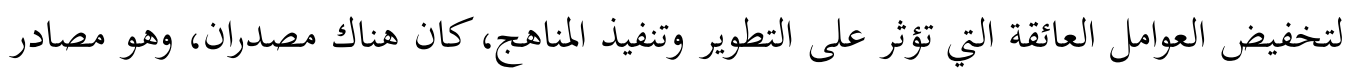

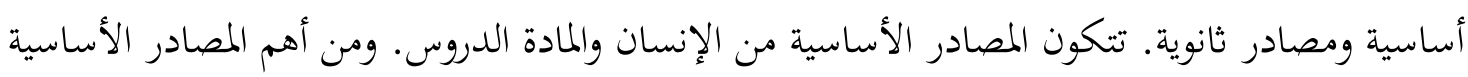

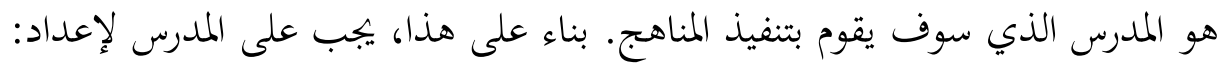

$$
\text { ما تمهارات والهيئة }
$$

توريط المدرس لاستنباط المقرر في تنفيذ المناهج

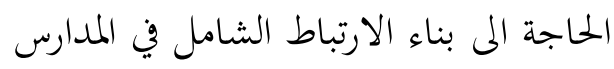

$$
\text { توريط ولي الطلاب في تنفيذها }
$$

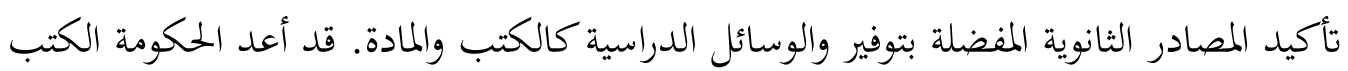

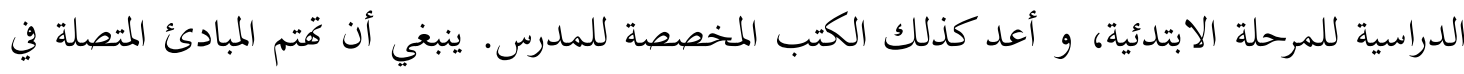

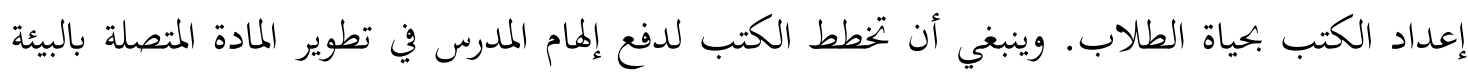

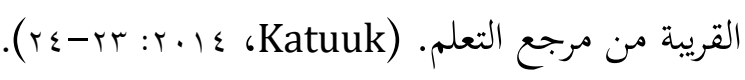

الحلاصة

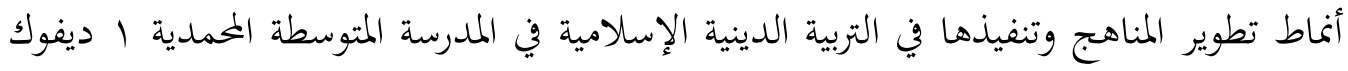

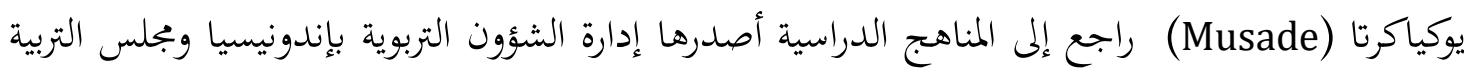

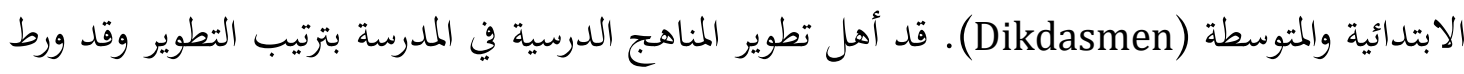

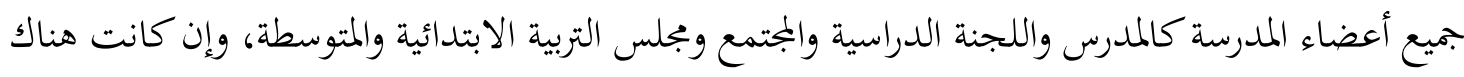

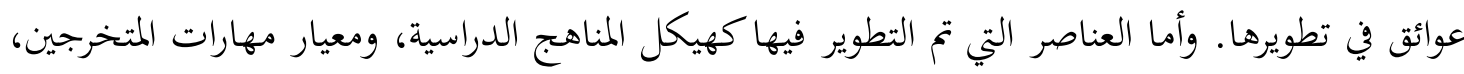

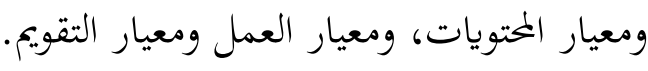

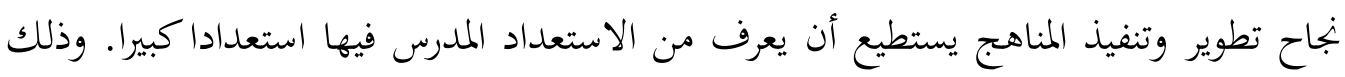

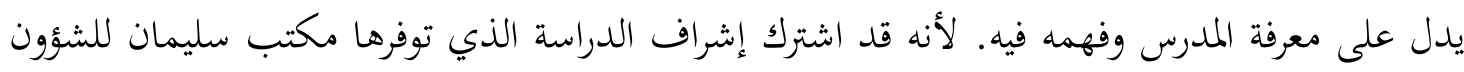

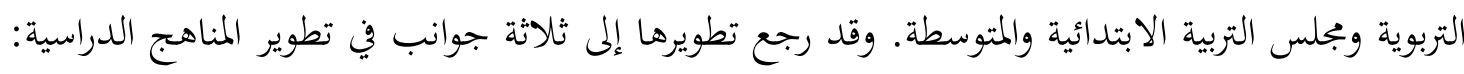
التخطيط والتنفيذ والتقويم التعليمي. 


\section{المراجع}

Bahri, S. (2011). Pengembangan Kurikulum Dasar dan Tujuannya. Jurnal Ilmiah Islam Futura, XI (1), 15-34. http://doi.org/10.22373/jiif.v11i1.61.

Dikdasmen, M. (2017). Kurikulum Pendidikan Al-Islam, Kemuhammadiyahan dan Bahasa Arab. Jakarta: Pimpinan Pusat Muhammadiyah.

Firman, A. J. (2017). Paradigma Hasan Langgulung tentang Konsep Fitrah dalam Pendidikan Islam. UHAMKA: Jurnal Pendidikan Islam, 8 (2), 123-143. https:// journal.uhamka.ac.id/index.php/jpi/article/view/806.

Fitroh. (2011). Pengembangan Kurikulum Berbasis Kompetensi dan Strategi Pencapaian. Studia Informatika: Jurnal Sistem Informasi, 4 (2), 1-7. http://journal.uinjkt.ac.id/ index.php/sisteminformasi/article/view/132

Gunawan, H. (2013). Kurikulum dan Pembelajaran Pendidikan Agama Islam. Bandung: Alfabeta.

Hamalik, O. (2008). Dasar-Dasar Pengembangan Kurikulum. Bandung: Remaja Rosdakarya.

Idi, A. (2007). Pengembangan Kurikulum dan Praktik. Yogyakarta: Ar-Ruzz Media.

Ismail, L., \& Risfaisal. (2017). Eksistensi Gerakan Muhammadiyah dalam Pendidikan di Era Modernisasi. Jurnal Equilibrium Pendidikan Sosiologi, V (2), 176-182. https:// doi.org/10.26618/equilibrium.v5i2.1049.

Jahya, Y. (2005). Pandangan Pelaksanaan Kurikulum Raudhatul Athfal. Jakarta: Departemen Agama RI.

Juwariyah. (2004). Kurikulum Ideal antara Cita dan Realita. Jurnal Pendidikan Agama Islam, 1 (2), 193-211.

Ja'far, H. (2015) Indonesian Islamic Education: Towards Science Development. Jurnal Walisongo, 23 (2), 331. http://doi.org/10.21580/ws.23.2.309.

Katuuk, D. A. (2014). Manajemen Implementasi Kurikulum. Jurnal Cakrawala Pendidikan, XXXIII (1), 13-26. https://doi.org/10.21831/cp.v1i1.1858.

Kunandar. (2007). Guru Profesional Implementasi Kurikulum Tingkat Satuan Pendidikan (KTSP) dan Sukses dalam Sertifikasi Guru. Jakarta: Raja Grafindo Persada.

Majid, A. (2012). Belajar dan Pembelajaran Pendidikan Agama Islam. Bandung: Remaja Rosdakarya.

Mansur, \& Junaidi, M. (2005). Rekonstruksi Sejarah Pendidikan Islam di Indonesia. Jakarta: Departemen Agama RI.

Mansur, R. (2016). Pengembangan Kurikulum Pendidikan Agama Islam Multikultural. Jurnal Kependidikan dan Keislaman FAI Unismea, 10 (2), 1-8. http://riset. unisma.ac.id/index.php/fai/article/view/165.

MOF, Y. (2015). Manajemen Implementasi Kurikulum dan Proses Pembelajaran. Jurnal Tarbiyah Islamiyah, 5 (2), 119-131. https://doi.org/10.18592/jt\%20ipai.v5i2. 1835.

Muhaimin. (2007). Pengembangan Kurikulum Pendidikan Agama Islam di Sekolah. Jakarta: Raja Grafindo Persada. 
Musthofa, I. (2012), تطوير منهج تعلم اللغة العربية, Jurnal Pendidikan Islam, 2(2), 322-323.

Nuryana, Z. (2017), Curriculum 2013 and the Future of Islamic Education in Indonesia, Jurnal International Seminar on Islamic Education, 2, (3), 257. https://doi.org/ 10.31227/osf.io/e2d9x.

Prihantoro. (2015), The Perspective of Curriculum in Indonesia on Environmental Education, International Journal of Research Studies in Education, 4, (1), 80. https://doi.org/ 10.5861/ijrse.2014.915.

Shofiyah. (2018). Prinsip-Prinsip Pengembangan Kurikulum dalam Upaya Meningkatkan Kualitas Pembelajaran. Edureligia: Jurnal Pendidikan Agama Islam, 2 (2), 122-130. https://doi.org/10.33650/edureligia.v2i2.464.

Sukmadinata, N. S. (2013). Pengembangan Kurikulum Teori dan Praktik. Bandung: Remaja Rosdakarya.

Suyatmini. (2017). Implementasi Kurikulum 2013 pada Pelaksanaan Pembelajaran Akuntansi di Sekolah Menengah Kejuruan. Jurnal Pendidikan Ilmu Sosial, 27 (1), 6068. https://doi.org/10.2317/jpis.v27i1.5120.

Wahyuni, S. (2016), Curriculum Development in Indonesian Context the Historical Perspectives and the Implementation. Jurnal UNIVERSUM, 10 (1), 74. https://doi.org/10.30762/universum.v10i1.225.

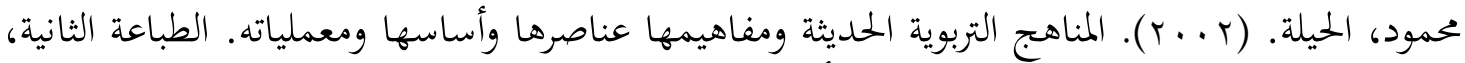

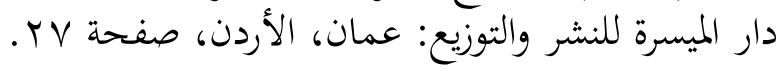

